\title{
VOLTAGE AND CURRENT BOOST TECHNIQUES
}

\author{
H. VIRANI PhD, MBA P.Eng, IEng, FIEIE, MIEEE
}

(Received 16 May 1996; In final form 17 June 1996)

The stability requirements for the current boosted are discussed in this paper.

Both internal and external compensation techniques are shown, along with necessary heatsink design information and typical circuits, including a self-oscillating switching regulator, and a voltage boost circuit.

\section{INTRODUCTION}

The basic voltage regulators will source up to $500 \mathrm{~mA}$, unassisted due to the large internal series pass transistor (Figures 1 and 2). Many applications required higher current levels or better efficiency for large inputoutput voltage differences. Instability problems encountered when adding an external transistor inside the regulator loop as discussed and solutions are offered for most applications.

\section{THE BASIC REGULATOR}

As mentioned in this paper of the voltage regulator series, it is desirable to operate the error amplifier in the unity gain voltage follower configuration. This test is a rigorous test for the error amplifier unless internal compensation is used. 


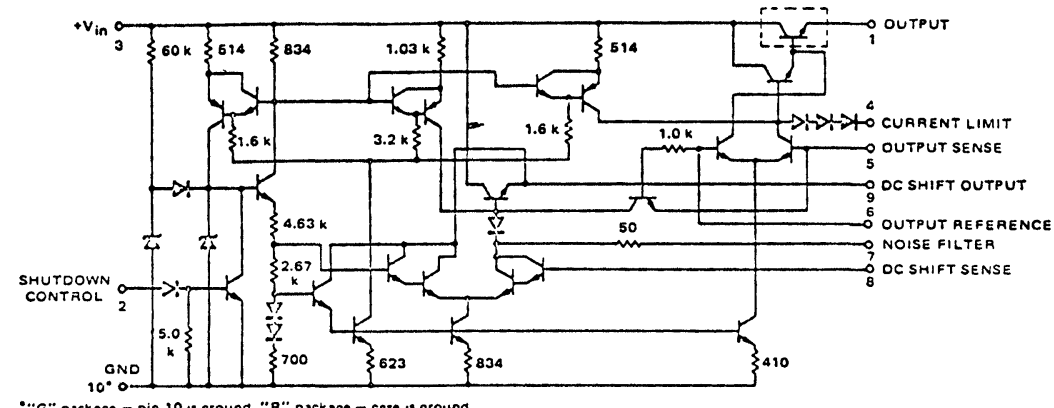

FIGURE 1

However, when using internal compensation, compromises must be made in the transient response as well as output impedance versus frequency characteristics.

Shown in Fig. 3 is an AC equivalent circuit for the basis error amplifier. A feedback amplifier approach can be used with $\mathrm{Ra}$ and $\mathrm{Ca}$ representing the inherent parasitic resistance at the collector of Q2. Solving the equation for the open loop gain AoL:

$$
\begin{gathered}
\mathrm{Ao}_{\mathrm{L}}(\mathrm{s})=\frac{\mathrm{V}_{\mathrm{o}}}{\mathrm{V}_{\mathrm{s}}}(\mathrm{s}) \\
\mathrm{Ao}_{\mathrm{L}}(\mathrm{s}) \approx \frac{\mathrm{A}_{0}}{1+\frac{\mathrm{S}}{\mathrm{WP}}}
\end{gathered}
$$

Where $\mathrm{A}_{0} \approx \frac{\beta_{0}^{2} \mathrm{RL}}{2 \mathrm{re}}$

$$
\begin{aligned}
\beta_{0}= & \text { low frequency common emitter current gain of series pass } \\
& \text { transistor. } \\
\text { re }= & \frac{\mathrm{kT}}{\mathrm{qIE}} \approx 26 \mathrm{mV} / \mathrm{I}_{\mathrm{E}} \text { at } 25^{\circ} \mathrm{C}
\end{aligned}
$$

IE is the emitter current of $Q_{1}$ and $Q_{2}$

and $\mathrm{Wp} \approx\left[\frac{1 / \mathrm{Ra}+1 / \beta_{0}^{2} \mathrm{RL}}{\mathrm{C}_{\mathrm{a}}+\mathrm{CL} / \beta_{0}^{2}}\right]$ 


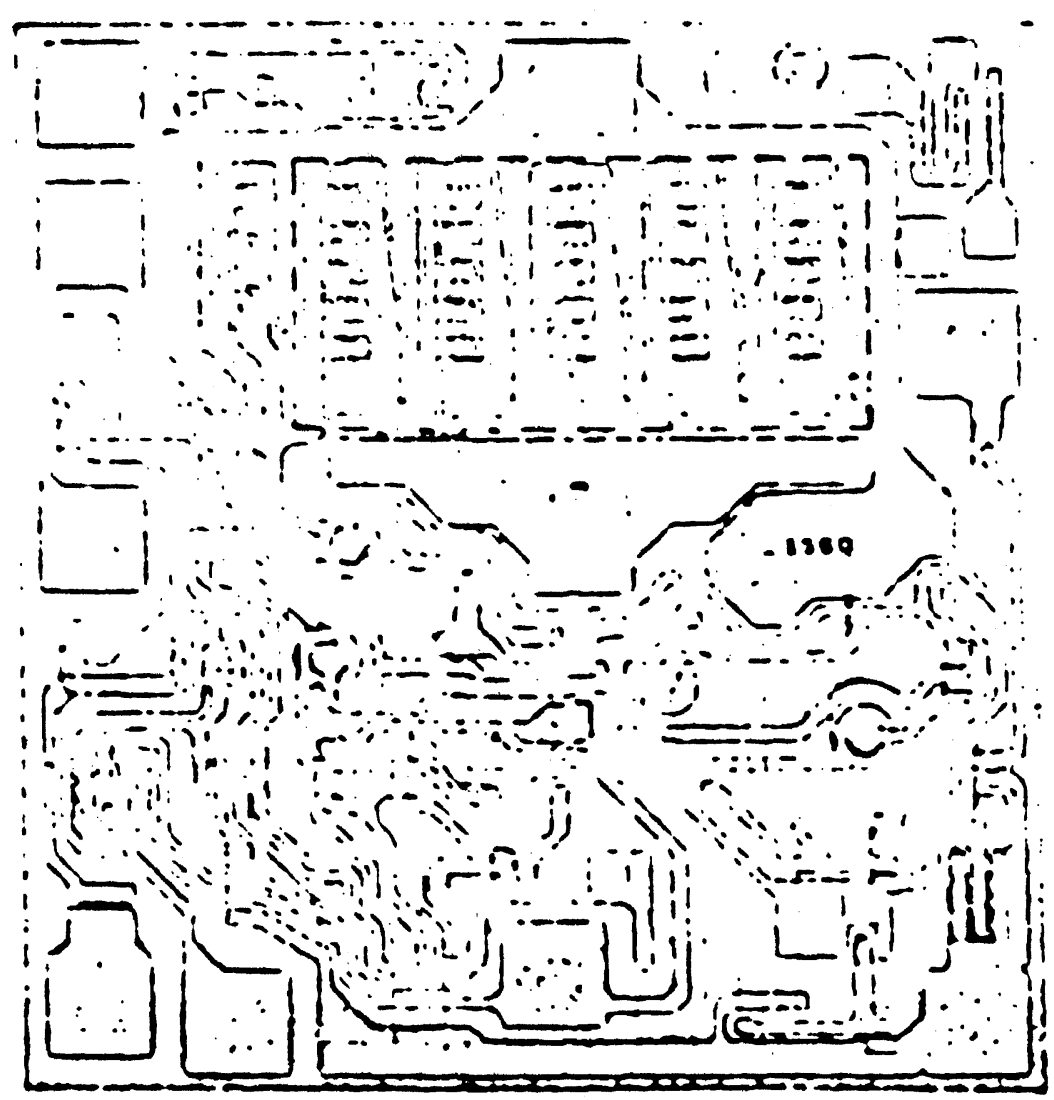

FIGURE 2

$$
\mathrm{Wp} \approx \frac{1}{\mathrm{CLRL}}
$$

With the feedback factor $\mathrm{f}$ equal to 1 , the loop gain $(\mathrm{T})$ is found.

$$
\begin{array}{r}
\mathrm{T}=\mathrm{AOL}^{\mathrm{f}} \\
\mathrm{T}=\mathrm{AOL} \\
\text { and } \mathrm{ZOL}=\frac{\mathrm{RL}}{1+\frac{\mathrm{S}}{\mathrm{Wp}}}
\end{array}
$$




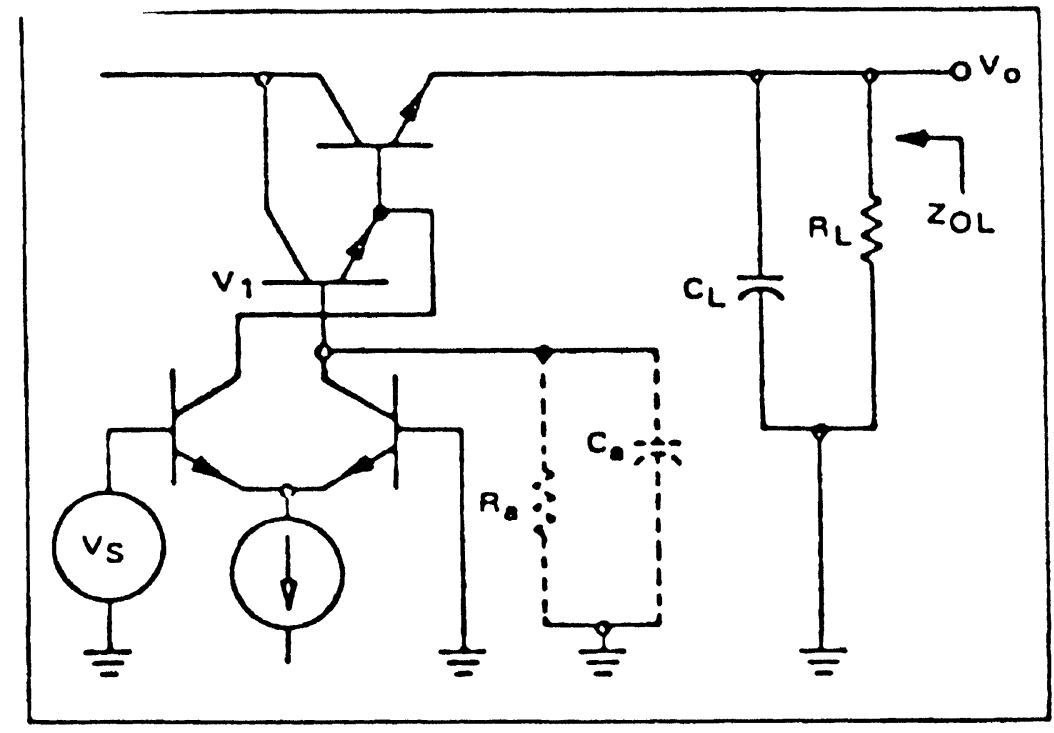

FIGURE 3

$$
\begin{gathered}
\mathrm{LCL}=\frac{\mathrm{ZOL}}{1+\mathrm{T}} \\
\mathrm{ZCL}=\left[\frac{2 \mathrm{re}}{\beta_{0}^{2}}\left(\frac{1}{1+\frac{\mathrm{S}}{\mathrm{A}_{0} \mathrm{Wp}}}\right)\right]
\end{gathered}
$$

From equation (2), it is seen that at the low frequencies of interest, the response of the amplifier is controlled by a dominant pole located at 1/RLCL. Thus, the loop stability is achieved even through loop gain is a maximum. From equation (3), the closed loop output impedance, ZCL, is also seen to be constant for frequencies well beyond $\mathrm{Wp}$ (the low frequency dominate pole). This occurs because both ZOL and $\mathrm{T}$ contain dominate poles at $\mathrm{Wp}$, which cancel, allowing ZCL to remain constant for frequencies well beyond those that are usually at interest. 


\section{CURRENT BOOST STABILITY CONSIDERATIONS}

Adding an external pass transistor for the circuit will alter some of the system parameters. However, it will provide the advantage of reduced output impedance and increased current capabilities. These improvements can add stability problems not evident in the basic unboosted configuration.

In figure 4, a hybrid model for a typical common emitter stage is shown.

Letting ZL = RLIICL, one can solve for YC where $\mathrm{Y}$ is the input impedance and, $Y=\frac{1}{-\mathrm{AZL}}$

$$
\begin{aligned}
\text { where }-\mathrm{A} & =\left[\frac{1+\mathrm{jWpbe}}{\mathrm{hfe}}\right] \\
\mathrm{p}^{\prime} \text { be } & =\left[\frac{\mathrm{hfe}}{\mathrm{gm}}\right]
\end{aligned}
$$

and $\mathrm{C}$ is the total collector-emitter capacitance from which one may obtain

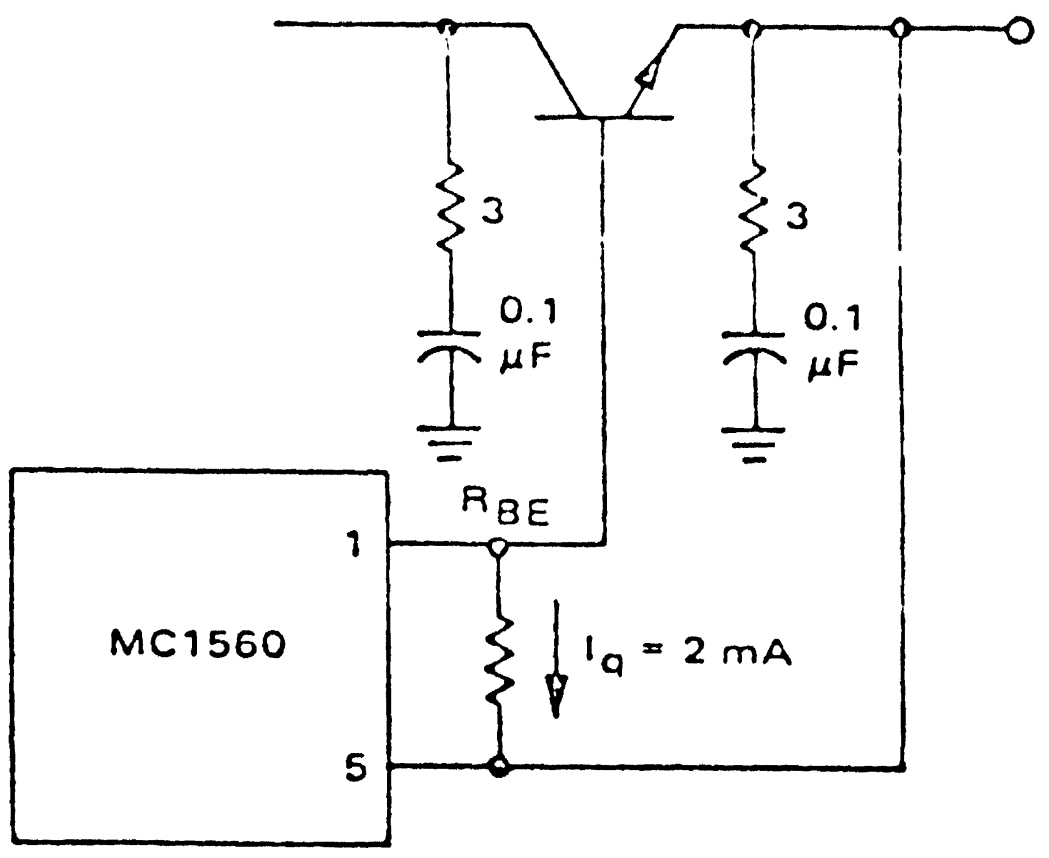

FIGURE 4 


$$
\begin{aligned}
\operatorname{Rin}=\operatorname{Re}\left\{\frac{1}{\mathrm{Y}}\right\} & =\frac{1}{1 / \mathrm{hfe} \mathrm{RL}-\mathrm{W}^{2} \mathrm{CCL} / \mathrm{gm}} \\
& =\frac{\mathrm{hfeRL}}{1-\mathrm{W}^{2} \mathrm{CCL} \gamma \mathrm{be}}
\end{aligned}
$$

From equation (4), it is seen that for sufficiently high frequencies Rin can become negative. Since in Series the load voltage is taken across RL, the line and load capacitance are introduced that aggravate the more complex problem. Equation (4) shows that light loading (a large RL) coupled with large value of CL can result in local instability in the pass transistor. Normally these could be compensated by increasing the source resistance or adding resistance in Series with the emitter. From equation (4), we also see that reducing $\mathrm{CL}$ is desirable from the standpoint of decreasing local instability. However, as shown in equation (2), CL and RL externally compensate the error amplifier and must be used to insure loop stability. With the addition of an external pass transistor, less current is required from the output loads and may result in less than 1 MA minimum quiescent current required from the regulator. In this condition, non-linearities can be encountered in the low-current (hfe) ranges and instability will again result. From a practical point of view, 0.6 volts is required to maintain the transistor in the active mode.

$$
\mathrm{RBE} \approx \frac{0.6 \mathrm{~V}}{1 \mathrm{~mA}}=600 \Omega
$$

Figure 4 also shows typical networks for decreasing the $\mathrm{Q}$ at both the collector and the emitter of the pass transistor. The decrease in $\mathrm{Q}$ is helpful in eliminating parasitic oscillations induced by stray lead inductance. If these networks are located at the pass transistor, then similar networks in most cases can be removed.

\section{INTERNAL COMPENSATION TECHNIQUES}

In our previous discussion, we were directed towards current boosting circuits that used external compensation to achieve loop stability. By doing this, it is possible to maintain or to improve all of the desirable fea- 
tures of the basic unboosted regulator. As previously mentioned, an internally compensated error amplifier is inferior to an externally compensated one since output impedance will now depend on frequency, and consequently, transient response will be poor. However, by internally compensating the error amplifier, one can easily stabilize the regulator, and the use of external elements will not degrade the regulation.

True transient response and output impedance versus frequency characteristics will be degraded somewhat. However, this may be of little consequence to many users. By introducing a pole and Zero internally, the open loop gain can be reduced for frequencies above those of interest. Also, RD (diode resistance) and C'L will introduce an additional element that will partially determine the closed loop response.

First let us consider the relationship of the external load resistance and capacitance as seen at the collector of the amplifier. Assuming perfect emitter followers, RL will now appear as $\beta_{1} \beta_{2} R L$ and likewise, CL looks like $\mathrm{CL} / \beta_{1} \beta_{2}$. This product $\beta_{1} \beta_{2}$ is the combined current gains of the internal and external pass transistor as shown in Figure 5

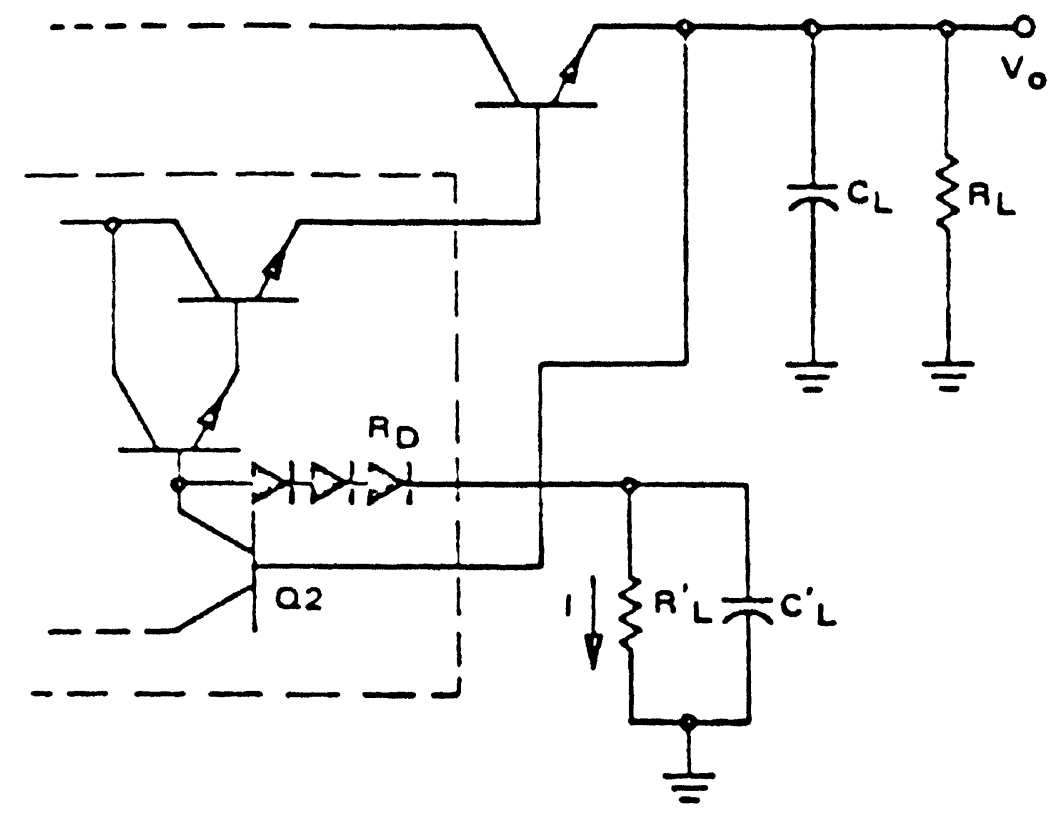

FIGURE 5 


$$
\begin{aligned}
& \mathrm{R}^{\prime} \mathrm{L}=\beta_{1} \beta_{2} \mathrm{RL} \\
& \mathrm{C}^{\prime} \mathrm{L}=\mathrm{CL} \beta_{1} \beta_{2}
\end{aligned}
$$

Since R'L will be effectively in parallel with RL (reference figure 5), the loop opening gain will be a function of RLIIRL

$$
\mathrm{AOL} \approx-\frac{\left(\text { RIIR'L }^{\prime}\right)}{2 \mathrm{re}}
$$

and if one assumes that $\mathrm{RL} \ll \mathrm{R}^{\prime} \mathrm{L}$, then AOL can be approximated as

$$
\mathrm{AOL} \approx \frac{-\mathrm{RL}}{2 \mathrm{re}}
$$

where re $=\frac{\mathrm{kT}}{\mathrm{qIE}} \approx \frac{26 \mathrm{mv}}{\mathrm{IE}}$ at $+25^{\circ} \mathrm{C}$

and $\mathrm{IE}=0.4 \mathrm{~mA}$

Therefore, the magnitude of the gain is approximated as

$$
|\mathrm{AOL}| \approx \frac{\mathrm{RL}}{\left(\frac{26 \times 10^{-3}}{0.4 \times 10^{-3}}\right)}
$$

from which one can obtain

$$
|\mathrm{AOL}|=\frac{\mathrm{RL}}{130}
$$

The value of RL should be such that it will be smaller than R'L but not so small that all base current for the internal pass transistor is diverted. A good compromise is to let RL draw about $0.1 \mathrm{~mA}$. The relationship between RL and Vout is then

$$
\mathrm{RL}(\mathrm{K} \Omega)=10 \times \text { Vout }
$$

$$
\begin{aligned}
& \text { For Vout }=10 \mathrm{~V}, \mathrm{RL}=100 \mathrm{k} \Omega \text { and } \\
& |\mathrm{AOL}|_{\mathrm{dc}}=\frac{100 \mathrm{k} \Omega}{130}=770=\mathrm{A}_{1} \text {. }
\end{aligned}
$$


To determine the first pole location, $\mathrm{W}_{1}$,

$$
\mathrm{W}_{1}=\frac{1}{\mathrm{R}^{\prime} \mathrm{L} 11 \mathrm{RL}} \frac{1}{\mathrm{CL}+\mathrm{CL}}
$$

then

$$
\mathrm{W}_{1} \approx \frac{1}{\mathrm{RLCL}}
$$

One sees that RL has little effect of the low-frequency dominant pole location, which is desirable. Also, since CL is typically 10 to $100 \mathrm{NF}, \mathrm{C}$ ' $\mathrm{L}$ can be indeed be much less than CL. To illustrate let $C L=0.1 \mathrm{NF}$, if $\beta_{1} \beta_{2}$ $\approx 50,000$

$$
\begin{aligned}
& \mathrm{CL}<50,000(0.1 \mu \mathrm{F}) \\
& \mathrm{CL}<5000 \mu \mathrm{F}
\end{aligned}
$$

This is not too great a restriction and if a larger value for $\mathrm{CL}$ is desired $\mathrm{C}$ can be increased to maintain the equality. Increasing the value of $\mathrm{C}$ will, however, lower the frequency response. For the mentioned example using equation 9 ,

$$
\begin{aligned}
\mathrm{W}_{1} & =\frac{1}{100 \mathrm{k} \Omega(0.1) 10^{-6}} \\
& =100 \mathrm{Rad} / \mathrm{s}
\end{aligned}
$$

The dominant Zero, $\mathrm{W}_{2}$ will be essentially due to the forward series diode resistance and the added compensation capacitor, C. Hence,

$$
\begin{aligned}
& \mathrm{W}_{2} \approx \frac{1}{\mathrm{RDC}} \\
& \mathrm{RD} \approx 3\left(\frac{\mathrm{kT}}{9 \mathrm{ID}}\right)
\end{aligned}
$$

where ID $=\frac{\text { Vout }}{\mathrm{R}}$ 
and $\mathrm{R}=100 \mathrm{~K} \Omega$

Hence for this example,

$$
\mathrm{RD}=3\left(\frac{26 \times 10^{-3}}{\mathrm{VO} / \mathrm{R}}\right)=\frac{7.8 \times 10^{3}}{\mathrm{~V}_{0}}
$$

$$
\begin{aligned}
& \text { for Vout }=10 \text { volts } \\
& \mathrm{RD}=780 \Omega \\
& \mathrm{W}_{2}=\frac{1}{7.8 \times 10^{2} \times 10^{-7}}=1.28 \times 10^{4} \mathrm{Rad} / \mathrm{s}
\end{aligned}
$$

Resulting gain drop between $\mathrm{W}_{1}$ and $\mathrm{W}_{2}$ is

$$
\left|\mathrm{A}_{2}\right|=\frac{\mathrm{W}_{2}}{\mathrm{~W}_{1}}=128
$$

Using equation (8) and (9) to determine $\mathrm{W}_{3}$ the high frequency pole location assume $\mathrm{RL}>\mathrm{RD}$

$$
\mathrm{W}_{3} \approx \frac{1}{\mathrm{RD}\left(\mathrm{C}^{\prime} \mathrm{L}+\mathrm{C}_{3}\right)}
$$

where $\mathrm{C}_{3} \approx 4 \mathrm{pF}$

Letting $C L=100 \mathrm{NF}$ and still assuming $\beta_{1} \beta_{2}=50000$

$$
\mathrm{C}^{\prime} \mathrm{L}=\frac{100 \mathrm{NF}}{50000}=2000 \mathrm{pF}
$$

$$
\text { Hence } \begin{aligned}
\mathrm{W}_{3} & =\frac{1}{\mathrm{RDCL}} \\
\mathrm{W}_{3} & =\frac{1}{780(2000) 10^{-12}} \\
\mathrm{~W}_{3} & =6.4 \times 10^{5} \mathrm{Rad} / \mathrm{S}
\end{aligned}
$$

and the odb crossover point is 


$$
\begin{gathered}
\mathrm{W}_{4} \approx \frac{\mathrm{AoL}}{\mathrm{A}_{2}} \mathrm{~W}_{3} \\
\mathrm{~W}_{4}=3.84 \times 10^{6} \mathrm{Rad} / \mathrm{s} .
\end{gathered}
$$

\section{OTHER DESIGN CONSIDERATIONS}

When utilizing a boost application, careful consideration must given to power dissipation. In addition, the safe areas and the pass to consider must be adhered to (figure 6 and 7). The data sheet shows the various voltage and current maximum as well as thermal resistances and should be referred to. A typical example will illustrate the basic procedure. For example let,

$$
\begin{gathered}
\text { Vin }=10 \text { volts } \\
\text { Vout }=-5 \text { volts }
\end{gathered}
$$

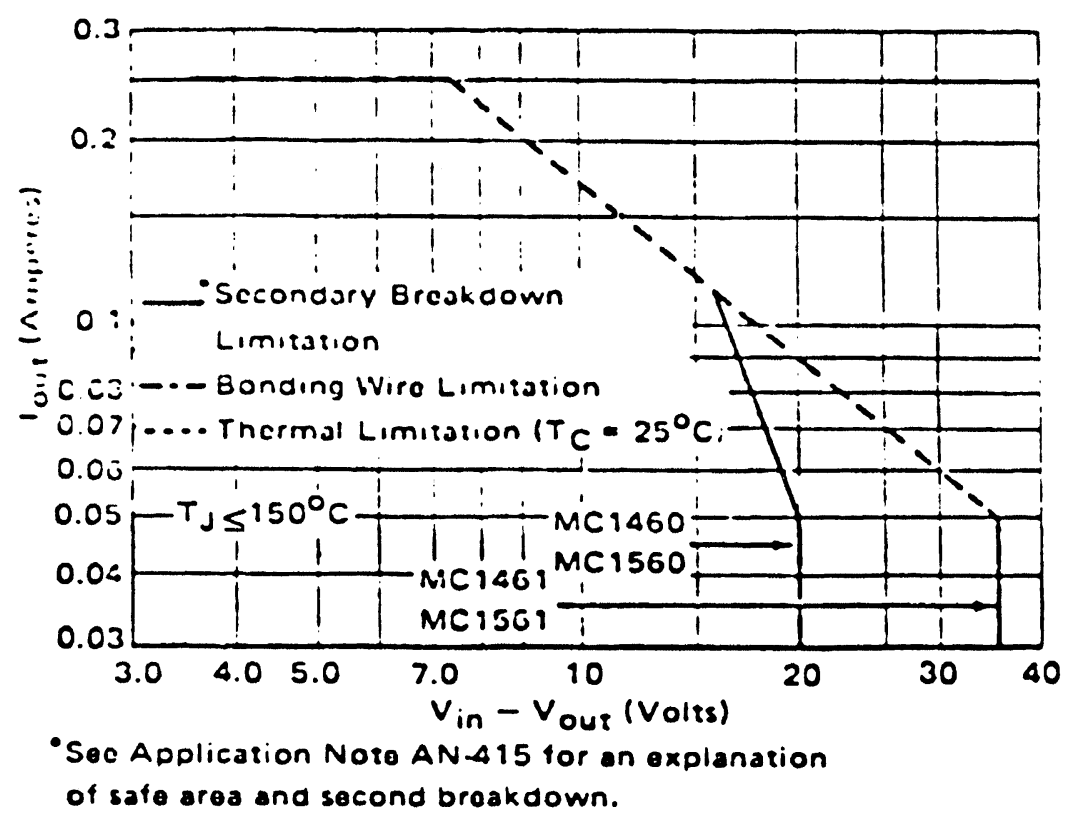

FIGURE 6 DC Safe Operating Area (“G” Package). 


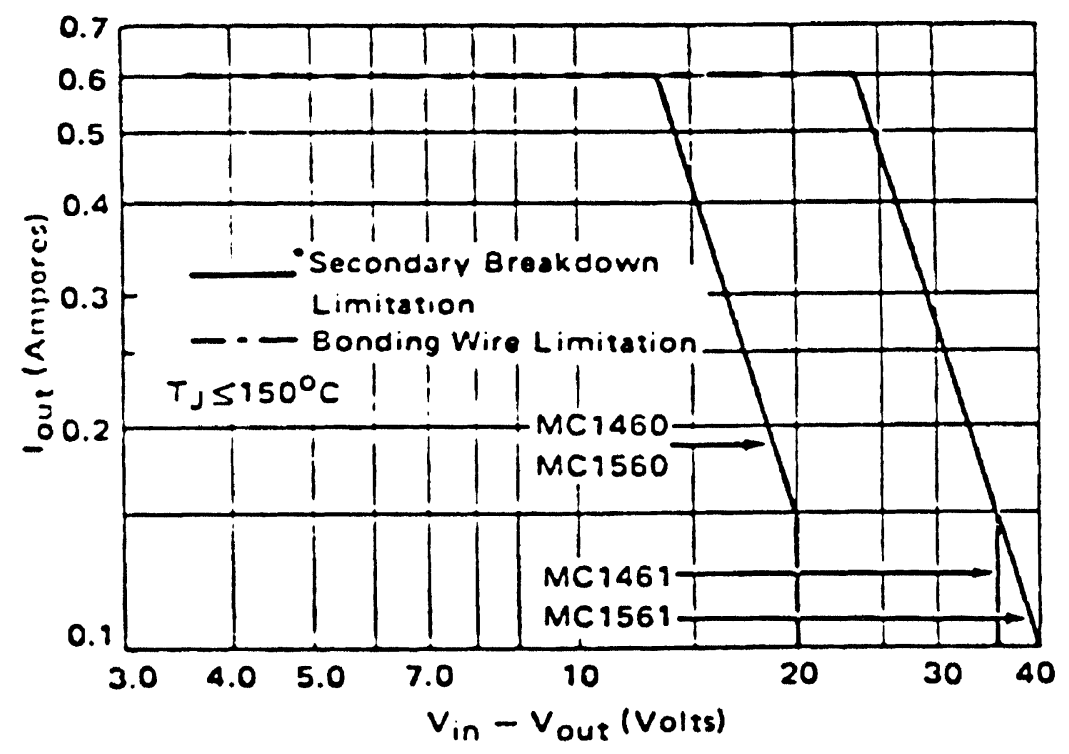

FIGURE 7 DC Safe Operating Area (“R” Package).

$$
\mathrm{I}_{\mathrm{sc}}=5 \text { amps }
$$

$$
0^{\circ} \mathrm{C} \leq \mathrm{TA} \leq+75^{\circ} \mathrm{C}
$$

Where $I_{\mathrm{sc}}$ is the short circuit current through the pass transistor. Notice the voltage differential is (Vin - Vout $)=5$ volts. This is based on regulation versus (Vin - Vout) consideration and also to allow for line fluctuations, since, referring of the data sheet, Vin(min) is 8.5 volts.

Thus for example, a 1.5 volt margin should be adequate. Assuming a worst case hfe of 15 ,

$$
I_{\mathrm{sc}}=\frac{I_{\mathrm{sc}}}{\text { hfe }}=\frac{5}{15}=334 \mathrm{~mA} .
$$

\section{CONCLUSION}

The fundamental high gain bandwidth need not be a deterrent to its use if ordinary RF precautions are observed or alternately, response time may be 
sacrificed to gain an extra margin of stability in less demanding circuits. Either way, the built-in, low-temperature coefficient reference voltage and high dc gain assure excellent regulation at all times for the configurations cited and many more. 

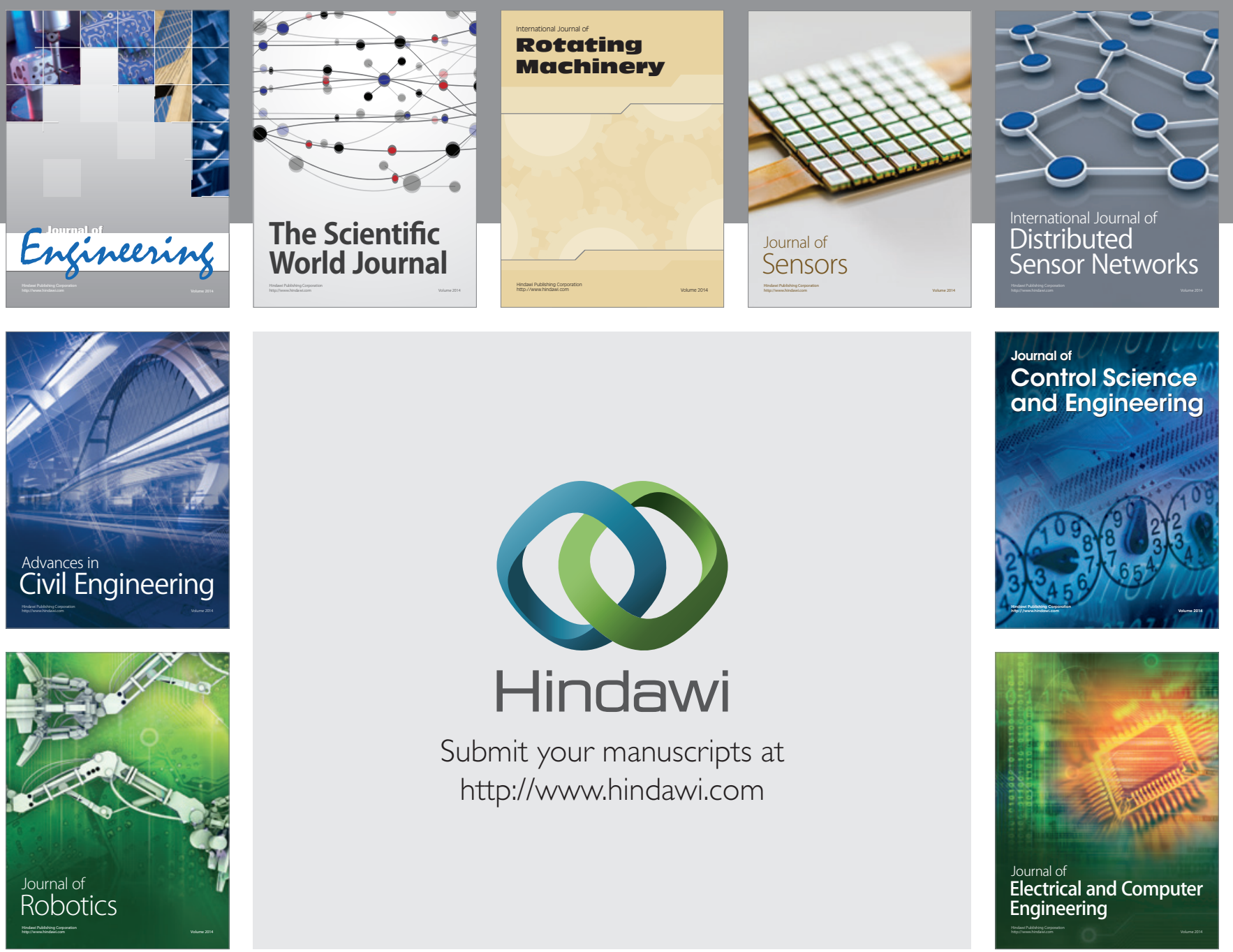

Submit your manuscripts at

http://www.hindawi.com
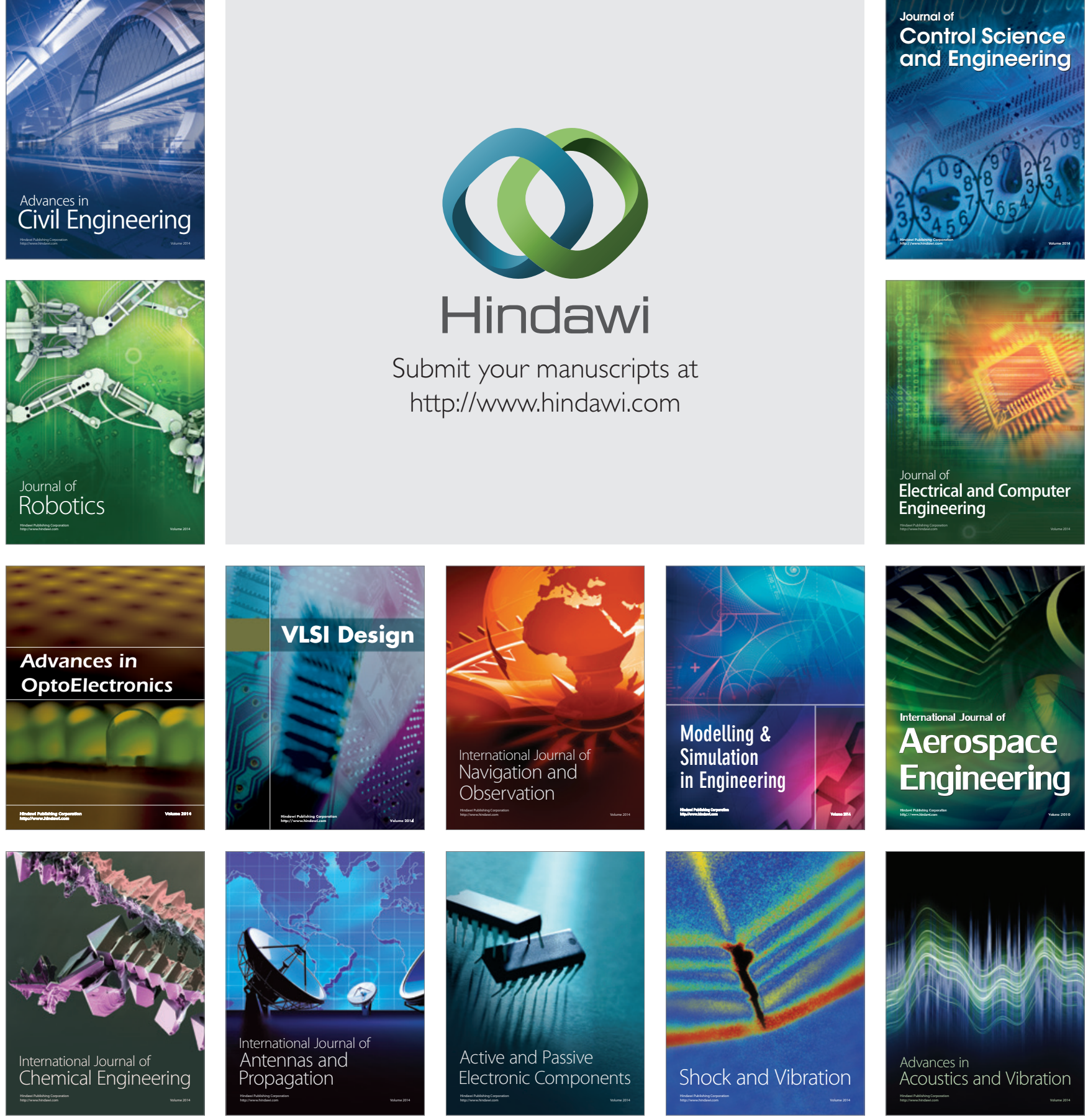